\title{
Catalytic Activity of Supported Rhodium(I) Complex for the Carbonylation of Nitrobenzene: Mechanism for Carbamate Formation
}

\author{
Jin Hyung Kim, Dae Won Kim, Minserk Cheong, Hoon Sik Kim, ${ }^{*}$ and Deb Kumar Mukherjee* \\ Department of Chemistry and Research institute for Basic Sciences, Kyung Hee University, Seoul 130-701, Korea \\ *E-mail: debkumarmukherjee@rediffmail.com (D.K.M),khs2004@khu.ac.kr (H.S.K) \\ Received March 10, 2010, Accepted April 12, 2010
}

\begin{abstract}
The investigation of the catalytic activity of supported rhodium $(\mathrm{I})$ complex $\left[\mathrm{Rh}(\mathrm{P}-\mathrm{S})(\mathrm{CO})_{2}\right](\mathrm{P}-\mathrm{S}$; polymer anchored salicylic acid) toward the reductive carbonylation of nitrobenzene in DMF medium has been reported. Use of basic cocatalysts in the reaction medium enhanced the percentage of more useful phenyl carbamates. Spectroscopic studies indicate that the reaction proceeds through a dimer species $\left[\mathrm{Rh}(\mathrm{HS})(\mathrm{CO})\left(\mathrm{C}(\mathrm{O}) \mathrm{OCH}_{3}\right)\left(\mu-\mathrm{OCH}_{3}\right)\right]_{2}$ and phenyl isocyanate is formed as an intermediate. A plausible reaction mechanism based on the identification of reactive intermediates from the soluble rhodium variety has been proposed for the carbonylation process.
\end{abstract}

Key Words: Carbonylation, Nitrobenzene, Isocyanate, Carbamates, Polymer-anchored

\section{Introduction}

The catalytic carbonylation of organic nitrocompounds is a reaction of high potential synthetic and industrial interest. Many important compounds such as ureas, carbamates, azo and azoxyarenes, oximes and several heterocyclic compounds can be selectively obtained by either reductive carbonylation of nitroaromatics $^{1-10}$ or oxidative carbonylation of anilines. ${ }^{11-14}$ Isocyanates, carbamates and ureas can now be obtained by either procedure without the use of the toxic and corrosive phosgene. The problem with oxidative carbonylation reactions is that $\mathrm{CO} / \mathrm{O}_{2}$ (or air) mixtures are explosive and though articles describe reactions run within the explosion limit, this is extremely unsafe even in the laboratory and is unacceptable on an industrial scale. Another disadvantage of the process is that oxidative carbonylation reactions generate water $\left(\mathrm{RNH}_{2}+\mathrm{CO}+1 / 2 \mathrm{O}_{2}+\mathrm{R}^{\prime} \mathrm{OH}\right.$ $\stackrel{\text { catalyst }}{\longrightarrow}$ RNHCOOR' $+\mathrm{H}_{2} \mathrm{O}$ ) as a stoichiometric by-product and water readily hydrolyses both carbamates and ureas at high temperatures. A promising phosgene free process to manufacture ureas and carbamates is the reductive carbonylation of nitro compounds with carbon monoxide in presence of transition metal catalysts. ${ }^{15-22}$ Most of the soluble palladium catalysts employed for reductive carbonylation reactions however suffer catalyst degradation and metal precipitation at some stages of the catalytic cycle under harsh reaction conditions. This causes great hindrance to catalyst modulation and recycling of expensive metal complexes. Although the price of precious metals employed and their reusability is an issue, the most important factor is that very high selectivities have to be achieved with minimum metal loss.

In homogeneous reactions catalyzed by organometallic compounds, the catalyst gets intimately involved with the reactants to form various intermediates during the course of the reaction. As per the recently published review, ${ }^{2}$ it is clear that deeper understanding of the reaction mechanism of the carbonylation system is required to gain better insight into the selectivity factor. In the present paper we have investigated the reductive carbonylation reaction of nitrobenzene to carbamates using a polystyrene anchored rhodium complex and made an attempt to find the catalytic pathway based on the isolation and characterization of key reactive intermediates from its soluble analogue. The tedious process of catalyst separation has also been eliminated by suspending the metal complex in a polymer matrix.

\section{Experimental}

Instrument and chemicals. Analytical grade reagents and freshly distilled solvents were used throughout the investigation. DMF was purified by drying over $\mathrm{CaH}_{2}$ under $\mathrm{N}_{2}$ for $24 \mathrm{~h}$ followed by distillation under reduced pressure. ${ }^{23} \mathrm{PhNH}_{2}$ was purified by vacuum distillation in an inert atmosphere prior to use. $\mathrm{CO}\left(99 \%\right.$, IOL-speciality gas division), $\mathrm{RhCl}_{3} \cdot 3 \mathrm{H}_{2} \mathrm{O}$ (Pressure Chemical company, Pittsburgh) and polystyrene beads crosslinked with $2 \%$ DVB [poly(styrene-co-divinyl benzene)] of particle size 100 - 200 mesh (Aldrich chemicals) were used as received. Vibrational, electronic and ${ }^{1} \mathrm{H}$ NMR spectra were taken with Perkin Elmer 883, Shimadzu MPC-3700 and Bruker 250 $\mathrm{MHz}$ instruments, respectively. Gas chromatographic analysis was performed with Chrompack CP-9000 using flame ionization detector with temperature programming from $120{ }^{\circ} \mathrm{C}$ to $260{ }^{\circ} \mathrm{C}$ at the rate $10{ }^{\circ} \mathrm{C} / \mathrm{min}$. The progress of the reaction was monitored by periodic analysis of the reaction mixture by GC technique. XPS study was made with VG-scientific ESCA lab mark E using $\mathrm{Al} \mathrm{K} \alpha$ as target material.

Carbonylation procedure. The carbonylation procedure using soluble and polystyrene anchored rhodium complexes as catalysts and nitrobenzene as a substrate has been described elsewhere. ${ }^{24}$ In a typical experiment, DMF solution $(10 \mathrm{~mL})$ of the catalyst $(0.02 \mathrm{mmol})$ and the substrate $(8 \mathrm{mmol})$ was taken in a $50 \mathrm{~mL}$ glass lined stainless steel autoclave provided with a magnetic bar. The reactor was first evacuated and flushed with nitrogen. After pumping out the nitrogen, it was immersed in a thermostated silicone oil bath preheated to the desired reaction temperature. The reaction mixture was then subjected to the required pressure of carbon monoxide which was maintained constant throughout the catalytic period. The products were identified and analyzed after subsequent work up by GC with 
FID using authentic samples for comparison. The column is 2meter $\times 1 / 8$ inch stainless steel with a stationary phase of $10 \%$ carbowax on chromosorb W-80 mesh support. During the catalytic recycling process, product after each run was filtered off using a Gooch crucible and the brown polystyrene beads collected at top were washed with acetone $(3 \times 20 \mathrm{~mL})$ before being reused with fresh substrate introduction.

\section{Preparation and isolation of the complexes.}

[Rh(HS)(CO)2] (1): The rhodium(I) complex (HS; salicylic acid) was prepared according to the literature method. ${ }^{25}$ The deep red solution mixture of $\mathrm{RhCl}_{3} \cdot 3 \mathrm{H}_{2} \mathrm{O}(0.26 \mathrm{~g}, 0.98 \mathrm{mmol})$ and salicylic acid $(0.26 \mathrm{~g}, 1.46 \mathrm{mmol})$ in dry, deoxygenated DMF $(10 \mathrm{~mL})$ was refluxed for $2 \mathrm{~h}$. The solution was cooled and the cold solution diluted with $20 \mathrm{~mL}$ of distilled water. The solution was refrigerated at $5{ }^{\circ} \mathrm{C}$ for $1 \mathrm{~h}$ when yellow precipitates were obtained. The precipitates after successive washing with water and acetone were dried under vacuum. The purity of the compound was checked by chemical analysis, IR and ${ }^{1} \mathrm{H}$ NMR studies. Though the yield was low $(\sim 40 \%)$, we could perform the catalytic studies in order to find the actual catalytic pathway followed by the polymer-anchored variety. With the salicylic acid attached to the polystyrene framework, the more economic recyclable catalyst could be prepared for the carbonylation reactions. ${ }^{1} \mathrm{H}-\mathrm{NMR}$ (DMSO- $d_{6}$ ): 3.3 (br, 1H), 6.9-7.8 (m, 4H); ${ }^{13}$ C-NMR (DMSO- $\left.d_{6}\right)$ : 112.7, 117.0, 125.3, 131.2, 132.6, 161.1, 163.2, 171.9, 195.7 .

$[\mathbf{R h}(\mathbf{H S})(\mathbf{C O})(\boldsymbol{\mu}-\mathbf{C O})]_{2}(2)$ : The solution of $\left[\mathrm{Rh}(\mathrm{HS})(\mathrm{CO})_{2}\right]$ $(0.34 \mathrm{~g}, 1.02 \mathrm{mmol})$ in dry deoxygenated DMF $(10 \mathrm{~mL})$ changed to green on stirring for $24 \mathrm{~h}$ under nitrogen. The solution was concentrated to $2-3 \mathrm{~mL}$ by vacuum evaporation at $60^{\circ} \mathrm{C}$, mixed with dry chloroform $(5 \mathrm{~mL})$ and kept at $0{ }^{\circ} \mathrm{C}$ for $24 \mathrm{~h}$ when the green crystalline precipitate separated out. This was washed with dry chloroform and dried under vacuum. ${ }^{241} \mathrm{H}$ NMR (DMSO- $\left.d_{6}\right)$ : 3.3 (br, 2H), 6.9-8.0 (m, 8H) ${ }^{13} \mathrm{C}$ NMR (DMSO- $d_{6}$ ): 112.7, 117.1, 125.3, 131.1, 132.6, 161.1, 163.2, 171.9, 195.7, 206.0 .

$\left[\mathbf{R h}(\mathbf{H S})\left(\boldsymbol{\mu} \text {-CO) }\left(\mathbf{P h N O}_{2}\right)\right]_{2}\right.$ (3): Dry $\mathrm{PhNO}_{2}(1 \mathrm{~mL})$ was added to the deep green solution obtained by stirring the DMF solution $(10 \mathrm{~mL})$ of $\left[\mathrm{Rh}(\mathrm{HS})(\mathrm{CO})_{2}\right](0.34 \mathrm{~g}, 1.02 \mathrm{mmol})$ for $24 \mathrm{~h}$ under nitrogen. Dry chloroform $(5 \mathrm{~mL})$ was added and the mixture was kept at $0{ }^{\circ} \mathrm{C}$ for $24 \mathrm{~h}$ when the deep green precipitate separated out. This was washed with chloroform and finally dried under vacuum. ${ }^{1} \mathrm{H}$ NMR (DMSO- $\left.d_{6}\right)$ : 3.3 (br, 2H), 6.9-8.1 (m, 16 H); ${ }^{13}$ C NMR (DMSO- $\left.d_{6}\right)$ : 112.8, 117.0, 119.1, 125.3, 128.5, 129.5, 130.2, 131.2, 132.6, 135.6, 136.1, 136.9, 161.1, 163.2, 171.9, 195.7.

$\left[\mathbf{R h}(\mathbf{H S})(\mathbf{C O})\left(\mathbf{C}(\mathbf{O}) \mathbf{O C H}_{3}\right)\left(\boldsymbol{\mu}-\mathbf{O C H}_{3}\right)\right]_{2}$ (4): A $50 \mathrm{~mL}$ stainless steel autoclave containing $\left[\mathrm{Rh}(\mathrm{HS})(\mathrm{CO})_{2}\right]$ was purged several times with CO. $o$-Nitrotoluene was dissolved in $15 \mathrm{~mL}$ of toluene and injected into the autoclave via an exhaust valve. After $5 \mathrm{~min}, 3 \mathrm{~mL}$ of methanol was injected in the same manner and the system was pressurized with $\mathrm{CO}(80 \mathrm{~atm})$ and heated to 80 ${ }^{\circ} \mathrm{C}$. After $24 \mathrm{~h}$, the reactor was cooled, the pressure was released and the solution transferred to a 2-necked $100 \mathrm{~mL}$ round-bottom flask. Solvent was removed under vacuum and the resulting brown oil was washed with $20 \mathrm{~mL}$ portions of diethyl ether and evacuated again. The brown tarry product was dissolved in a minimum quantity of benzene and the process of stirring and washing with dry ether was continued until the brown compound separated out. Light brown solid thus isolated was subjected to ${ }^{1} \mathrm{H}$ NMR and IR studies for characterization. ${ }^{24,26}$ Brown solid, ${ }^{1} \mathrm{H}$ NMR (ppm, DMSO- $\left.d_{6}\right) 3.03$ (s, 3H, $\left.\mathrm{OCH}_{3}\right) ; 3.66$ (s, 3H, $\left.\mathrm{OCH}_{3}\right) ; 3.3$ (br, $\left.2 \mathrm{H}, \mathrm{OH}\right) ; 6.9-8.1(\mathrm{~m}, 8 \mathrm{H}) ;{ }^{13} \mathrm{C} \mathrm{NMR}$ (ppm,

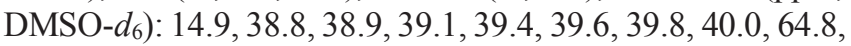
$112.7,116.9,118.9,125.2,130.1,131.1,135.4,136.1,161.2$, 163.1, 171.9, 206.0. IR (KBr, cm $\left.{ }^{-1}\right) 3230,2078,1655,1610$, 1108, 889, 658; Anal: (Found: C, 38.38\%; H, 3.22\%; Rh, 28.6; Calcd.: C, 38.50; H, 3.23\%).

[Rh(P-S)(CO) 2$](\mathbf{5})$ : The polymer-anchored complex [Rh(OO$\left.\mathrm{CC}_{6} \mathrm{H}_{4} \mathrm{OCH}_{2}-\mathrm{P}\right)(\mathrm{CO})_{2}$ ], $\mathrm{P}=$ poly(styrene-co-divinylbenzene) having the same coordination geometry as the salicylic acid linked rhodium(I) carbonyl complex was prepared as shown in Scheme $1 .^{27-29}$ Polystyrene beads were first chloromethylated by the known procedure of Pepper et. al. ${ }^{27}$ The chloromethylated polymer was next treated with THF solution of salicylic acid for $48 \mathrm{~h}$ to replace $\sim 90 \%$ of the chlorine with the acid group. The grey colored beads were then refluxed with $50 \mathrm{~mL} \mathrm{DMF}$ solution of $\mathrm{RhCl}_{3} \cdot 3 \mathrm{H}_{2} \mathrm{O}$ for $6 \mathrm{~h}$. At the end of the reflux period the brown colored beads were washed with acetone and dried under vacuum. The beads can be stored in air for several days without any noticeable change in color or bead fragmentation.

Characterization. The compounds $\left[\mathrm{Rh}(\mathrm{P}-\mathrm{S})(\mathrm{CO})_{2}\right],[\mathrm{Rh}(\mathrm{HS})$ $(\mathrm{CO})(\mu-\mathrm{CO})]_{2},\left[\mathrm{Rh}(\mathrm{HS})(\mu-\mathrm{CO})\left(\mathrm{PhNO}_{2}\right)\right]_{2}$ and $[\mathrm{Rh}(\mathrm{HS})(\mathrm{CO})$ $\left.\left(\mathrm{COOCH}_{3}\right)\left(\mu-\mathrm{OCH}_{3}\right)\right]_{2}$ were characterized on the basis of their analytical data and vibrational spectral data (Tablel 1). ${ }^{1} \mathrm{H}$ NMR and XPS data were also collected for these complexes. IR peaks at $1575 \mathrm{~cm}^{-1}\left(v_{\mathrm{CO}}\right.$, as $), 1380 \mathrm{~cm}^{-1}\left(v_{\mathrm{CO}}, \mathrm{s}\right)$ and in the region 3230 $\mathrm{cm}^{-1}\left(\mathrm{~V}_{\mathrm{OH}}\right)$ are present in the spectra of the soluble complexes indicating the presence of coordinated salicylate in all of them. Compared to the IR spectrum of $\mathbf{1}$, the spectrum of $\mathbf{2}$ shows the appearance of a new peak at $1848 \mathrm{~cm}^{-1}\left(v_{\mathrm{CO}}\right.$, bridged) at the cost of one $\mathrm{CO}$ (terminal) peak at $2075 \mathrm{~cm}^{-1}$. The other CO peak at $2010 \mathrm{~cm}^{-1}$ remains almost unchanged. It has therefore been suggested that the starting complex [Rh(HS)(CO) 2 , in DMF medium, undergoes dimerisation through $\mathrm{CO}$ bridging to form a penta-coordinated rhodium(I) complex containing both terminal

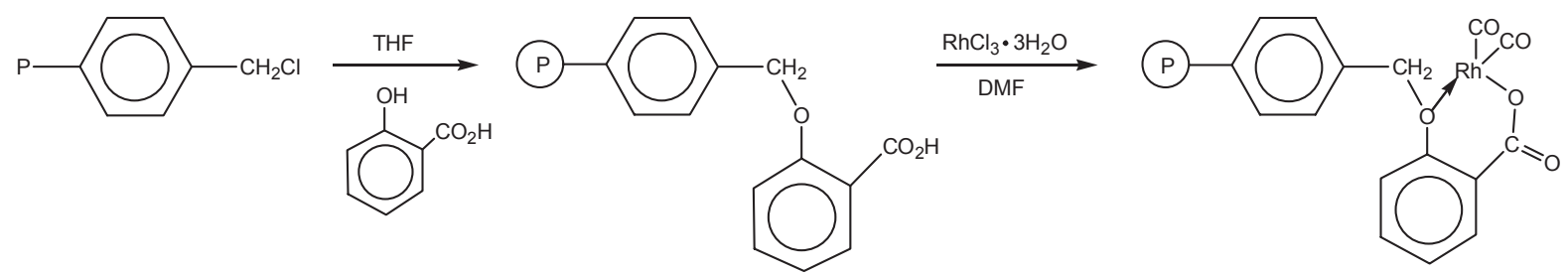

Polymer-bound rhodium( I ) carbonyl complex

Scheme 1. preparation of polystyrene-anchored rhodium(I) carbonyl complex 
Table 1. Analytical and $\mathrm{IR}^{a}$ data of the compounds

\begin{tabular}{|c|c|c|c|c|c|c|c|c|c|}
\hline Compounds & $v_{\mathrm{CO}}$ & $v_{\mathrm{OH}}$ & $v_{\mathrm{OCO}}$ & $\mathrm{V}_{\mathrm{OCH}_{3}}$ & $v_{\mathrm{NO}_{2}}$ & $\mathrm{C} \%$ & $\mathrm{H} \%$ & $\mathrm{~N} \%$ & $\mathrm{Rh} \%$ \\
\hline$\left[\mathrm{Rh}(\mathrm{HS})(\mathrm{CO})_{2}\right](\mathbf{1})$ & $\begin{array}{l}2075 \\
2010\end{array}$ & 3232 & $\begin{array}{l}1578(\mathrm{a}) \\
1380(\mathrm{~s})\end{array}$ & & & $\begin{array}{c}36.24 \\
(36.36)\end{array}$ & $\begin{array}{c}1.62 \\
(1.69)\end{array}$ & & 30.5 \\
\hline$[\mathrm{Rh}(\mathrm{HS})(\mathrm{CO})(\mu-\mathrm{CO})]_{2}(\mathbf{2})$ & $\begin{array}{l}2012 \\
1847\end{array}$ & 3230 & $\begin{array}{l}1570 \\
1377\end{array}$ & & & $\begin{array}{c}36.40 \\
(36.36)\end{array}$ & $\begin{array}{c}1.71 \\
(1.69)\end{array}$ & & 29.8 \\
\hline$\left[\mathrm{Rh}(\mathrm{HS})(\mu-\mathrm{CO})\left(\mathrm{PhNO}_{2}\right)\right]_{2}(\mathbf{3})$ & 1848 & 3224 & $\begin{array}{l}1572 \\
1374\end{array}$ & & $\begin{array}{l}1520 \\
1350\end{array}$ & $\begin{array}{c}42.82 \\
(42.86)\end{array}$ & $\begin{array}{l}2.53 \\
(2.57)\end{array}$ & $\begin{array}{c}3.55 \\
(3.57)\end{array}$ & 22.2 \\
\hline$\left[\mathrm{Rh}(\mathrm{HS})(\mathrm{CO})\left(\mathrm{C}(\mathrm{O}) \mathrm{OCH}_{3}\right)\left(\mu-\mathrm{OCH}_{3}\right)\right]_{2}(4)$ & 2008 & 3228 & $\begin{array}{l}1577 \text { (a) } \\
1383(\mathrm{~s})\end{array}$ & $\begin{array}{l}1610 \\
1655\end{array}$ & & $\begin{array}{c}38.38 \\
(38.50)\end{array}$ & $\begin{array}{c}3.22 \\
(3.23)\end{array}$ & & 28.6 \\
\hline$\left[\mathrm{Rh}(\mathrm{P}-\mathrm{S})(\mathrm{CO})_{2}\right](\mathbf{5})$ & $\begin{array}{l}2077 \\
1887\end{array}$ & & $\begin{array}{l}1574 \\
1377\end{array}$ & & & & & & 1.78 \\
\hline
\end{tabular}

${ }^{a} \mathrm{KBr}$ pellets, all values are in $\mathrm{cm}^{-1}$; analytical values in parentheses are calculated values.

and bridged carbonyl groups. The spectrum of $\mathbf{3}$ exhibits two new peaks at 1520 and $1350 \mathrm{~cm}^{-1}$ due to the coordinated $\mathrm{PhNO}_{2}$ and only the bridged carbonyl peak at $1848 \mathrm{~cm}^{-1}$ is present. In case of complex 4, the peaks at 1610 and $1655 \mathrm{~cm}^{-1}$ in the $v_{\mathrm{CO}}$ region is characteristic of the methoxy carbonyl ligand. ${ }^{30,31}$

The ${ }^{1} \mathrm{H}$ NMR spectrum (ppm, DMSO- $d_{6}$ ) of complex (1) exhibit multiple signals in the region $6.9-7.9$ (phenyl protons) and a broad signal at 3.32 (hydroxy). New ${ }^{1} \mathrm{H}$ NMR signals at 3.03 and $3.66 \mathrm{ppm}$ of complex (4) are attributed to $\mathrm{CH}_{3}$ protons of $\mathrm{C}(\mathrm{O}) \mathrm{OCH}_{3}$ groups and to the $\mathrm{O}-\mathrm{CH}_{3}$ protons of the bridging ligands respectively. ${ }^{32,33}$ The rhodium content in each of the complexes was determined by refluxing them with concentrated hydrochloric acid or $1: 1 \mathrm{HNO}_{3}$ for $6 \mathrm{~h}$ and then estimating the metal concentration in the solution by atomic absorption spectrometry at wavelength $255.6 \mathrm{~nm}$ using air-acetylene flame.

XPS (X-ray photoelectron) study of the compounds were carried out in the range $290-320 \mathrm{eV}$ using $\mathrm{Al} \mathrm{K \alpha}$ as target material in order to determine the oxidation state of metal in them. The $3 \mathrm{~d}_{5 / 2}$ and $3 \mathrm{~d}_{3 / 2}$ levels of rhodium in the complexes $1,2,3$ and 5 have binding energies in the vicinity of $\sim 308$ and $\sim 312 \mathrm{eV}$ respectively. These energies are comparable with +1 oxidation state of rhodium. ${ }^{34}$ The binding energy for the isolated complex 4 was found to be $310.2\left(3 \mathrm{~d}_{5 / 2}\right)$ and $314.2 \mathrm{eV}\left(3 \mathrm{~d}_{3 / 2}\right)$ which suggests the presence of $\mathrm{Rh}(\mathrm{III})$ in the species as compared to the standard material $\mathrm{RhCl}_{3} \cdot 3 \mathrm{H}_{2} \mathrm{O}$. To avoid possible X-ray induced metal reduction in the polymer host, measurements were made with a reduced power of the X-ray source of $10 \mathrm{KV}, 10 \mathrm{~mA}$. Survey spectra were recorded for all the samples in the range $0-800 \mathrm{eV}$ with a step of $0.5 \mathrm{eV}$.

\section{Results and Discussions}

Herein, we report our findings on the highly reactive and selective reductive carbonylation of nitrobenzene in good yields using $\left[\mathrm{Rh}(\mathrm{P}-\mathrm{S})(\mathrm{CO})_{2}\right] / \mathrm{CH}_{3} \mathrm{OH} / \mathrm{CH}_{3} \mathrm{ONa}$ as the catalytic system in a weekly coordinating solvent like DMF. The reaction is selective to diphenylurea formation if we use only methanol and no sodium methoxide in the system as shown in (Eq. 1). If sodium methoxide is used along with methanol, keeping other factors unchanged the product obtained in this case is methylphenyl carbamate and no diphenylurea (Eq. 2).

$$
\begin{array}{cc}
\mathrm{PhNO}_{2} & \frac{\mathrm{Rh}(\mathrm{P}-\mathrm{S})(\mathrm{CO})_{2}}{\mathrm{MeOH}, \mathrm{DMF}} \mathrm{PhNHCONHPh} \\
\mathrm{P}_{\mathrm{CO}}=80 \mathrm{~atm}, \mathrm{~T}=100{ }^{\circ} \mathrm{C} \\
\mathrm{PhNO}_{2} & \stackrel{\mathrm{Rh}(\mathrm{P}-\mathrm{S})(\mathrm{CO})_{2}}{\mathrm{MeOH}, \mathrm{DMF}, \mathrm{MeONa}} \longrightarrow \mathrm{PhNHCOOMe} \\
\mathrm{P}_{\mathrm{CO}}=80 \mathrm{~atm}, \mathrm{~T}=100{ }^{\circ} \mathrm{C}
\end{array}
$$

We investigated the effect of carbon monoxide pressure, reaction temperature, alcohol concentration and cocatalysts on the catalytic system and assigned a tentative reaction mechanism based on our findings and isolation of key reactive intermediates from the soluble rhodium salicylate complex.

Effect of $\mathrm{CO}$ pressure and temperature. The carbonylation of nitrobenzene when performed at the room temperature $\left(30^{\circ} \mathrm{C}\right)$ and low carbon monoxide pressure (20 atm), even in the presence of methanol it did not yield any product. Effect of carbon monoxide pressure and temperature on the carbonylation of nitrobenzene was therefore studied to optimize the yield of products. Highest conversion of $\mathrm{PhNO}_{2}(100 \%)$ to diphenylurea (DPU) was achieved at $80 \mathrm{~atm}$ and $100^{\circ} \mathrm{C}$ and at a methanol concentration of $60 \mathrm{mmol}$ as per eq. 1. Higher methanol concentration increased the yield of aniline at the cost of DPU. The DMF solution of the isolated complexes $\mathbf{2}$ and $\mathbf{3}$ were also used to study the carbonylation of nitrobenzene under similar reaction conditions. No product formation occurred even with these complexes at low temperature (less than $40^{\circ} \mathrm{C}$ ) and at carbon monoxide pressure maintained below $40 \mathrm{~atm}$. However at $\mathrm{P}_{\mathrm{CO}}=80$ atm and temperature of $100{ }^{\circ} \mathrm{C}, 100 \%$ conversion of $\mathrm{PhNO}_{2}$ was noticed. The product in both these cases was diphenylurea $(\sim 70)$ and aniline (15-20\%).

In order to find out whether any transformation of the isolated compound $\left[\mathrm{Rh}(\mathrm{HS})\left(\mathrm{PhNO}_{2}\right)(m-\mathrm{CO})\right]_{2}$ occur in solution at higher temperature, IR spectra of the DMF solution of the compound 3 at $100{ }^{\circ} \mathrm{C}$ was taken. The spectra exhibit a new peak at 2008 $\mathrm{cm}^{-1}$ ( $v_{\mathrm{CO}}$ terminal) indicating the cleavage of the carbonylbridged rhodium complex into the substrate coordinated monomer species in DMF solution. This was as expected as the dimer 


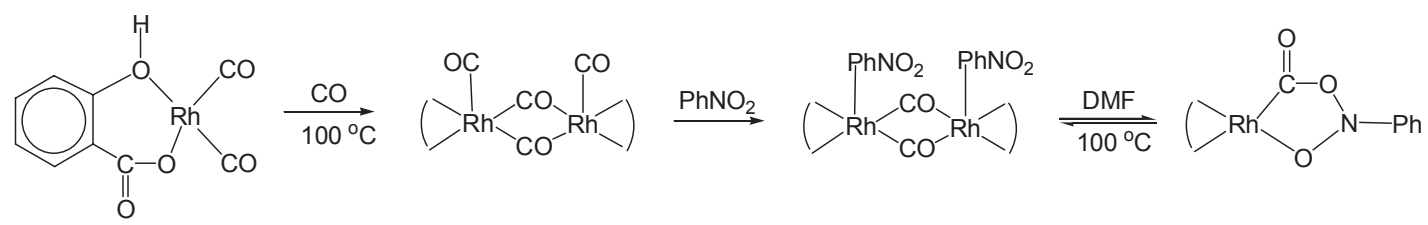

Scheme 2. substrate coordination to rhodium carbonyl complex

species would be unstable at such high temperature in DMF solution. It is worth mentioning here that when studying $\mathrm{Pd} / \mathrm{HI}$ catalyzed carbonylation of methanol, Chaudhari and co-workers isolated the dimeric $\left[\left(\mathrm{PdI}_{2}\right)_{2}(\mu-\mathrm{I})_{2}\right]^{2-}$ species and showed that it converts to $\left[\mathrm{PdI}_{3}(\mathrm{CO})\right]^{-}$under $\mathrm{CO}$ pressure. ${ }^{35}$ Though we have isolated the substrate coordinated rhodium species (designated as complex 3), we are not sure of its real existence or formation in the high CO pressure, high temperature catalytic run in DMF solution. Since nitrosobenzene and phenyl nitrine intermediates have been predicted for the palladium and ruthenium complexes by various groups, ${ }^{2}$ we speculated Scheme 2 for the initial stages of our catalytic carbonylation reactions. This could best explain the isolation of intermediates from the starting complex and the formation of aniline as an associated product in all cases.

$\left[\mathrm{Rh}(\mathrm{HS})(\mu-\mathrm{CO}) \mathrm{PhNO}_{2}\right]$ as shown in Scheme 2 is believed to be the catalytically active species formed under the given set of conditions though all our effort to isolate it in the pure state was unsuccessful.

Effect of alcohol. In the absence of any cosolvent, the bulk of the nitrobenzene remained unchanged and GC analysis of the final product mixture indicated the presence of a small amount of aniline (4 - 5\%). This was probably due to moisture in the solvent contaminated from the air or during subsequent work-up procedure. Carbonylation of nitrobenzene in completely dry DMF at $100{ }^{\circ} \mathrm{C}$ in the $\mathrm{P}_{\mathrm{CO}}$ range of $40-80$ atmospheres did not occur even after $24 \mathrm{~h}$ of reaction. The presence of a cosolvent such as $\mathrm{ROH}\left(\mathrm{R}=\mathrm{CH}_{3}, \mathrm{C}_{2} \mathrm{H}_{5}\right)$ or $\mathrm{H}_{2} \mathrm{O}$ was therefore necessary for the reaction between $\mathrm{PhNO}_{2}$ and $\mathrm{CO}$ to proceed under high pressure and high temperature conditions. Presence of moisture in the system greatly hinders the catalytic conversion to DPU and almost $90 \%$ aniline was recorded. High aniline formation may also be due to hydrolysis of any DPU formed (reaction 3).

$$
(\mathrm{PhNHCONHPh})+\mathrm{H}_{2} \mathrm{O} \rightarrow 2 \mathrm{PhNH}_{2}+\mathrm{CO}_{2}
$$

Carbonylation reactions in presence of both cosolvent and cocatalyst were tried out to optimize the yield of the more useful phenyl carbamates. Investigations were made with both acidic and basic cocatalysts in the presence of alcohol in the reaction medium. In presence of methanol concentration ( $60 \mathrm{mmol})$, addition of acid cocatalysts such as $\mathrm{FeCl}_{3}, \mathrm{AlCl}_{3}$ or $p$-toluenesulphonic acid increased only the yield of aniline without any formation of the desired carbamates. The acid cocatalysts were therefore replaced by the basic ones like $\mathrm{KOH}, \mathrm{Et}_{3} \mathrm{~N}$, Pyridine, $\mathrm{RONa}\left(\mathrm{R}=\mathrm{CH}_{3}, \mathrm{C}_{2} \mathrm{H}_{5}\right)$ and the results have been tabulated (Table 2). $70 \%$ selectivity of carbamate formation was achieved under optimum reaction conditions using $\mathrm{NaOMe}$ as cocatalyst (Entry 10, Table 2). Any variation of reaction parameters did not produce $100 \%$ selectivity. Small amount of $N$-phenyl form- amide detected in most cases may be due to direct interaction of aniline and carbon monoxide (Equation 4).

$$
\mathrm{PhNH}_{2}+\mathrm{CO} \rightarrow \mathrm{HCONHPh}
$$

Effect of solvent and cocatalysts. Weakly coordinating solvents were found to be more efficient and most of the catalytic runs were taken in DMF and DMSO. Very sluggish reaction occurs in strong coordinating solvents like $\mathrm{CH}_{3} \mathrm{CN}$ or in non-polar solvents like $\mathrm{C}_{6} \mathrm{H}_{6}, \mathrm{C}_{6} \mathrm{H}_{5} \mathrm{CH}_{3}$, hexane. The non-polar solvents probably cannot break the dinuclear rhodium complex to the corresponding monomer to any appreciable extent, while in strong coordinating medium, the corresponding solvent-adducts do not allow the formation of a metal-substrate complex. The solvents sufficiently strong to form the solvent adduct by carbonyl bridge cleavage and sufficiently labile to favour metalsubstrate complex formation appear to be most suitable for the present investigation.

The cocatalysts that were effective are all basic in nature and vary greatly in the efficiencies. The best one is $\mathrm{RONa}\left(\mathrm{R}=\mathrm{CH}_{3}\right.$, $\mathrm{C}_{2} \mathrm{H}_{5}$ ) followed by $\mathrm{Et}_{3} \mathrm{~N}$ and pyridine. The experimental results show that the yield of carbamate is enhanced by basic cocatalysts while the acidic ones have the reverse effect. Increase in cocatalyst concentration from $1 \mathrm{mmol}$ to $10 \mathrm{mmol}$ did not however affect the yield of carbamate formation nor has any effect on product distribution. Carbamate formation probably requires the presence of $\mathrm{OR}^{-}$ion which is provided to different extent by different basic cocatalysts according to the following reaction :

$$
\mathrm{ROH}+\mathrm{B} \rightarrow \mathrm{RO}^{-}+\mathrm{BH}^{+}
$$

Effect of the polymer anchored ligand. To study the efficiency of the polymer supported ligand as a recyclable catalyst, $\mathrm{RhCl}_{3}$. $3 \mathrm{H}_{2} \mathrm{O}$ was also subjected to similar catalytic condition as employed for the supported catalyst $\left[\mathrm{Rh}(\mathrm{P}-\mathrm{S})(\mathrm{CO})_{2}\right]$. Spontaneous reduction of $\mathrm{Rh}(\mathrm{III})$ to $\mathrm{Rh}(\mathrm{I})$ under the reaction conditions was expected for $\mathrm{RhCl}_{3}$ and we hoped to recover rhodium(I) carbonyl chloro complex of the type $\left[\mathrm{Rh}(\mathrm{Cl})(\mathrm{CO})_{2}(\mathrm{DMF})\right]$ from the solution mixture. To our surprise, we recovered a white substance which was difficult to characterize. $\mathrm{RhCl}_{3} \cdot 3 \mathrm{H}_{2} \mathrm{O}$ when used as a catalyst for the carbonylation reaction of nitrobenzene did not yield any urea or carbamate under similar reaction conditions. The product was $10-12 \%$ aniline and most of the substrate was recovered. In order to prepare a recyclable catalyst with similar coordination environment we opted for the polystyrene anchored salicylate ligand.

Though the DMF soluble rhodium catalyst (designated as 1) undergo successful carbonylation reaction to produce useful carbamates, it is extremely difficult to isolate the rhodium complex 
Table 2. Carbonylation ${ }^{a}$ of nitrobenzene with polymer anchored rhodium catalyst in different cocatalysts and cosolvents

\begin{tabular}{|c|c|c|c|c|c|c|c|}
\hline Entry & $\begin{array}{c}\text { Cocatalyst } \\
(2 \mathrm{mmol})\end{array}$ & $\begin{array}{l}\text { Cosolvent } \\
(60 \mathrm{mmol})\end{array}$ & $\begin{array}{c}(\%) \text { conv. } \\
\mathrm{PhNO}_{2}\end{array}$ & $\mathrm{DPU}^{b}$ & $\begin{array}{l}\text { Selectivity \% } \\
\text { PC }^{c}\end{array}$ & $\mathrm{PhNH}_{2}$ & $\mathrm{NPF}^{d}$ \\
\hline 1 & & $\mathrm{H}_{2} \mathrm{O}$ & 100 & - & - & 91 & 5 \\
\hline 2 & & $\mathrm{CH}_{3} \mathrm{OH}$ & 92 & 55 & - & 28 & 10 \\
\hline 3 & & $\mathrm{C}_{2} \mathrm{H}_{5} \mathrm{OH}$ & 90 & 52 & - & 24 & 12 \\
\hline 4 & $\mathrm{FeCl}_{3}$ & - & 20 & 05 & - & 12 & - \\
\hline 5 & $\mathrm{AlCl}_{3}$ & - & 40 & 05 & - & 29 & - \\
\hline 6 & py & $\mathrm{CH}_{3} \mathrm{OH}$ & 70 & - & 50 & 26 & 10 \\
\hline 7 & $\mathrm{FeCl}_{3}$ & $\mathrm{CH}_{3} \mathrm{OH}$ & 50 & 25 & - & 15 & 4 \\
\hline 8 & $\mathrm{Et}_{3} \mathrm{~N}$ & $\mathrm{CH}_{3} \mathrm{OH}$ & 80 & - & 55 & 28 & 10 \\
\hline 9 & $\mathrm{NaOMe}$ & - & 15 & - & - & 7 & - \\
\hline 10 & $\mathrm{NaOMe}$ & $\mathrm{CH}_{3} \mathrm{OH}$ & 94 & - & 70 & 20 & - \\
\hline 11 & $\mathrm{NaOEt}$ & $\mathrm{C}_{2} \mathrm{H}_{5} \mathrm{OH}$ & 92 & - & 64 & 20 & 5 \\
\hline 12 & $\mathrm{KOH}$ & $\mathrm{CH}_{3} \mathrm{OH}$ & 86 & 22 & 4 & 30 & 9 \\
\hline
\end{tabular}

${ }^{a}$ Conditions: $\mathrm{PhNO}_{2}=8 \mathrm{mmol}$, Catal. $=$ Rh. Content $=0.002 \mathrm{mmol}$. Medium $=$ DMF, T $=100{ }^{\circ} \mathrm{C}, \mathrm{t}=16 \mathrm{~h}, \mathrm{Pco}=80$ atm. ${ }^{b} N, N^{\prime}$-diphenylurea. ${ }^{c} N$-phenylcarbamate. ${ }^{d} N$-phenylformamide.

Table 3. Recycling study with Catalyst $\mathrm{Rh}(\mathrm{P}-\mathrm{S})(\mathrm{CO})_{2}$ in methanol

\begin{tabular}{cccc}
\hline $\begin{array}{c}\text { Catalytic } \\
\text { Cycle }\end{array}$ & $\begin{array}{c}\text { \% Conversion of } \\
\text { nitrobenzene }\end{array}$ & $\begin{array}{c}\text { \% Yield of } \\
\text { MPC }\end{array}$ & $\begin{array}{c}\text { TOF } \\
\left(\min ^{-1}\right)^{a}\end{array}$ \\
\hline Fresh & 94 & 74 & 4.43 \\
Recycle 1 & 94 & 77 & 4.43 \\
Recycle 2 & 93 & 77 & 4.48 \\
Recycle 3 & 92 & 71 & 4.52 \\
Recycle 4 & 90 & 70 & 4.62 \\
Recycle 5 & 90 & 68 & 4.62 \\
\hline
\end{tabular}

Reaction Condition: $\mathrm{PhNO}_{2}=8 \mathrm{mmol}$; $\mathrm{Cat}=\mathrm{Rh}$ content $=0.002 \mathrm{mmol}$; isolated yield refers to $\mathrm{GC}$ analysis, $\mathrm{P}_{\mathrm{CO}}=80 \mathrm{~atm}, \mathrm{~T}=100{ }^{\circ} \mathrm{C}, \mathrm{t}=16 \mathrm{~h}, \mathrm{CH}_{3}-$ $\mathrm{OH}=60 \mathrm{mmol}, \mathrm{CH}_{3} \mathrm{ONa}=2 \mathrm{mmol} ;{ }^{a} \mathrm{TOF}=$ Turn over frequency (moles of $\mathrm{PhNO}_{2} /$ moles of catalyst) $\mathrm{min}^{-1}$.

from the reaction mixture at the end in a reusable form. The polystyrene variety of the rhodium catalyst can however be readily collected by simple gravity separation and can be recycled (Table 3) without any significant loss in efficiency. At the end of the fifth recycle run, the polymer beads were treated with $1: 1$
$\mathrm{HNO}_{3}$ solution and the rhodium content was again determined by AAS as described before. Analysis shows that the rhodium content in the polymer variety has decreased by $15 \%$ compared to the freshly prepared complex after five catalytic cycles. This loss did not hamper the performance or efficiency of the supported rhodium catalyst. This rapid loss after five catalytic cycles may be due to bead fragmentation in solution or swelling of beads which could not be conclusively established (FTIR peaks show no major changes). As mentioned earlier, we have used several non-polar and polar solvents but DMF and DMSO works out to be best. After treating the polymer-anchored variety with ethanolic solution of $\mathrm{KCN}$ for 24 hours to remove all rhodium from the polymer beads, we conducted the carbonylation reaction keeping all parameters same. In this case, we noticed no product formation, not even aniline. The heterogenous variety of the rhodium complex seems in all probability responsible for repeated carbonylation reactions.

Proposed mechanism for carbamate formation. Based on the above observations and identification of the reactive intermediates, the mechanism shown in Scheme 3 has been tentatively

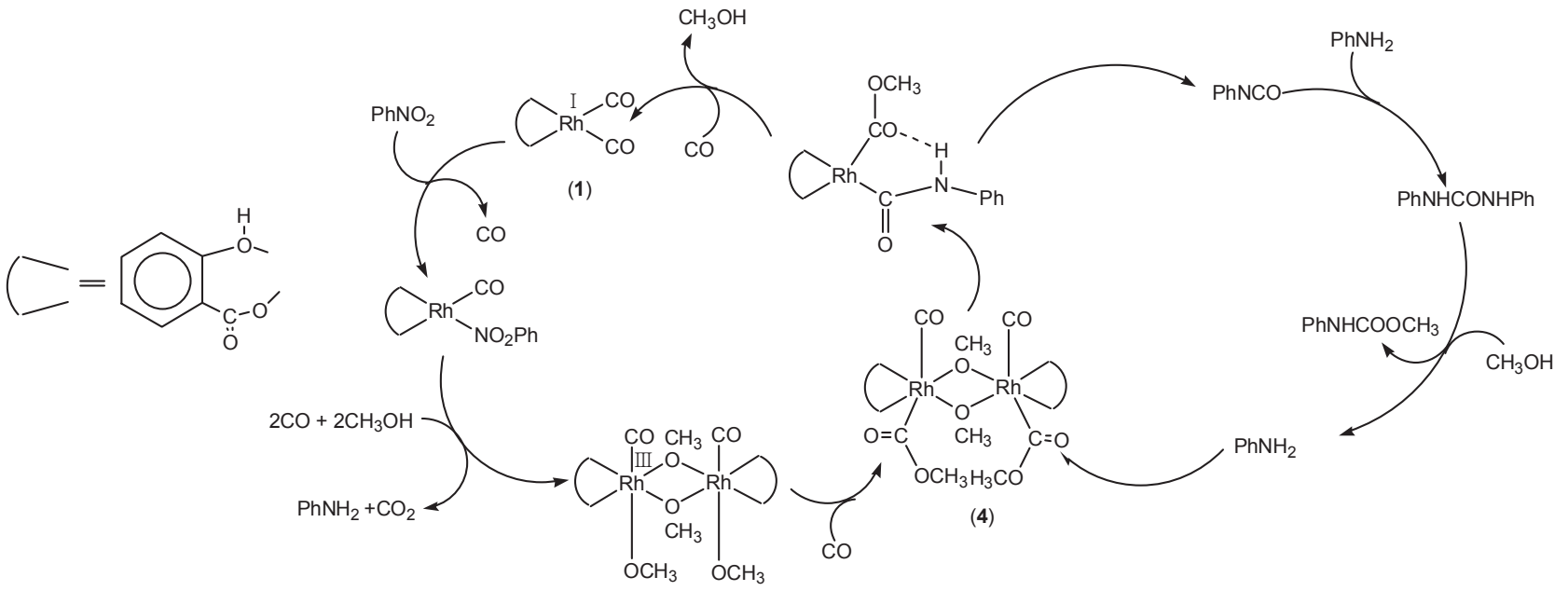

Scheme 3. Mechanism to carbamate formation using soluble rhodium (I) carbonyl complex 


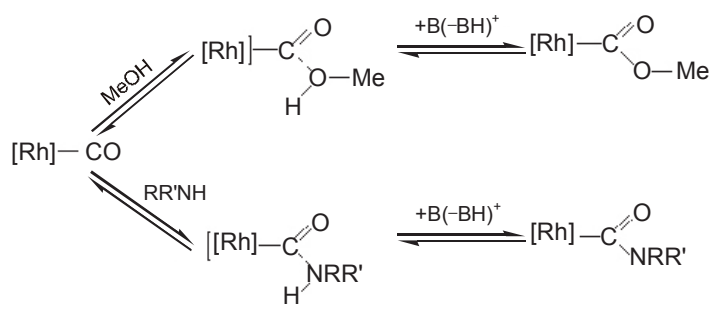

B: base (including aniline)

Scheme 4. Equilibria involved in alkoxycarbonyl or carbamoyl complex formation

assigned to the carbonylation process using the soluble rhodium catalyst. In the scheme we have indicated formation of the substrate coordinated carbonyl species as the first step, followed by release of aniline and nucleophilic attack of the alcohol to the rhodium metal. Formation of the intermediate compound 4 (Scheme 3 ) requires $\mathrm{CO}$ insertion in one of the stages and this explains the requirement of high carbon monoxide pressure for the carbonylation process. Very low $\mathrm{P}_{\mathrm{CO}}$ prevents the formation and isolation of the intermediate and therefore no carbonylation products were observed under such conditions even at high methanol concentration.

An effort was also made to support our catalytic cycle by treating a solution of $p$-toluidine and dry methanol in a septum sealed vial with $p$-tolyl isocyanate (Aldrich chemical) as tried by Gladfelter and coworkers. ${ }^{30,32}$ Visible amounts of $N, N^{\prime}$-ditolylurea were noticed within $10 \mathrm{~min}$ at ambient temperature. The solution in the vial was analyzed using gas chromatography at an interval of $30 \mathrm{~min}$ for $3 \mathrm{~h}$. No trace of carbamate could be detected at any stage of the reaction. The fact that isocyanate formed at an intermediate stage is immediately taken up by the amine resulting in the formation of urea is therefore demonstrated. Formation of carbamate at this stage seemed unlikely due to lower basicity of $\mathrm{CH}_{3} \mathrm{OH}$ compared to $\mathrm{PhNH}_{2}$. When sodium methoxide (cocatalyst) is added to the catalytic system, concentration of $\mathrm{CH}_{3} \mathrm{O}^{-}$in the system increases and this facilitates the formation of carbamate rather than urea.

The reactivity of palladium(II) complexes with $\mathrm{CO}$ and amines has been investigated in several papers. ${ }^{36-38}$ In general the authors have reported mono or bis-carbamoyl complexes depending on the reaction conditions and the identity of the species involved. A less clear situation occurs when a primary or secondary amine is reacted with the palladium complex and $\mathrm{CO}$ in the presence of an alcohol. Carbamoyl complexes have been reported in some cases whereas alkoxycarbonyl complexes are obtained in others. ${ }^{37,38}$ To our knowledge no explanation for this behavior has been given in the literature.

We have put forward the argument that nucleophilic attack of the alcohol on a coordinated $\mathrm{CO}$ group generates an unstable adduct that eventually produces the alkoxycarbonyl group after deprotonation by a base as shown in Scheme 4. In our case the released aniline acts as the base and this augurs well with the isolation of the six-coordinated rhodium (III) complex (complex 4). Yamamoto has also shown in his studies that amines never attack the palladium atom in a series of palladium complexes when CO is present. ${ }^{39,40}$ The intermediate formation of rhodium carbamoyl or amido complexes is therefore unlikely and formation of alkoxy complexes as predicted is possible under the present circumstances.

\section{Conclusion}

In conclusion, reductive carbonylation of nitrobenzene by the polymer-anchored rhodium catalyst has been demonstrated. Under the catalytic system we could obtain either diphenylurea or phenyl carbamate depending upon the applied conditions. In all of the stoichiometric reactions, the isocyanate has been predicted to be formed which is immediately trapped by amines or alkoxides to form the observed products. Aniline forms the diphenylurea because of its higher basicity compared to alcohols. Incorporation of basic cocatalysts like sodium methoxide and sodium ethoxide leads to high yield of carbamate formation. The polystyrene-supported rhodium complex can be recycled several times without substantial loss of catalytic efficiency.

Acknowledgments. We acknowledge financial support by a grant (AC3-101) from Carbon Dioxide Reduction \& Sequestration Research Center, one of the 21st Century Frontier Programs funded by the Ministry of Science and Technology of Korean government.

\section{References}

1. Cenini, S.; Ragaini, F. Catalytic Reductive Carbonylation of Organic Nitro Compounds; Kluwer Academic publishers: Dordrecht, The Netherlands, 1996.

2. Ragaini, F. Dalton Trans. 2009, 6251.

3. Muzart, J. Tetrahedron 2005, 61(40), 9423.

4. Ragaini, F.; Cenini, S. J. Mol. Catal. 1996, 109, 1.

5. Lee, Ch. W.; Cho, N. S.; Kim, K. D.; Oh, J. S.; Lee, S. M.; Lee, J. S J. Mol. Catal. 1993, 81, 17.

6. Mukherjee, D. K.; Palit, B. K.; Saha, C. R. J. Mol. Catal. 1994, 91, 19.

7. Gaonkar, S. R.; Sapre, N. Y.; Bhaduri, S.; Kumar, G. S. Macromolecules 1990, 23(14), 3533.

8. Mukherjee, D. K.; Saha, C. R. J. Catal. 2002, 210, 255.

9. Tafesh, A. M.; Weiguny, J. Chem. Review 1996, 96, 2035.

10. Skupinska, J.; Karpinska, M.; Olowek, M. Appl. Catal. A: Gen. 2004, 267, 59.

11. Gabriele, B.; Salerno, G.; Costa, M.; Chiusoli, G. P. J. Organomet. Chem. 2003, 68, 219.

12. Kanagasabapathy, S.; Thangaraj, A.; Gupte, S. P.; Chaudhuri, R. V. catalyst Lett. 1994, 25, 361.

13. Stahl, S. Angew. Chem. Int. Ed. 2004, 43, 3400.

14. Lee, S. M.; Cho, N. S.; Kim, K. D.; Oh, J. S.; Lee, C. W.; Lee, J. S. J. Mol. Catal. 1992, 73, 43.

15. Sherlock, S. J.; Boyd, D. C.; Moasser B.; Gladfelter, W. L. Inorg. Chem. 1991, 30, 3626.

16. Kunin, A. J.; Noirot, M. D.; Gladfelter, W. L. J. Am. Chem. Soc. 1989, 111, 2739.

17. Islam, S. M.; Mal, D.; Palit, B. K.; Saha, C. R. J. Mol. Catal. A: Chemical 1999, 142, 169.

18. Basu, A.; Bhaduri, S.; Khwaja, H.; Sharma, R. K. Proceedings of the Indian National Science Academy, Part-A: Physical Sciences 1986, 52, 831 .

19. Jayashree, S.; Seayad, A,; Gupte, S. P.; Chaudhari, R. V. Catal. Lett. 1999, 58, 213.

20. Macho, V.; Kralic, M.; Halmo, F. J. Mol. Catal. A: Chem. 1996, 109,119

21. Orejon, A.; Masdeu-Bulto, A. M.; Salagre, P.; Castillon, S.; Claver, 
C.; Padilla, A.; Almena, B.; Seranno, F. L. Ind. and Eng. Chem. Res. 2008, 47, 8032

22. Gargulak, J. D.; Hoffmann, R. D.; Gladfelter, W. L. J. Mol. Catal. 1991, 68, 289

23. Riddick, J. A.; Bunger, W. B. Physical Properties and Methods of Purification-Organic Solvents; Vol. 2, 1986; Weissberger.

24. Mukherjee, D. K.; Saha, C. R. J. Mol. Catal. A: Chemical 2003, $193,4$.

25. Kwaskowska-chec, E.; Ziolkowski, J. J. Trans. Met. Chem. 1983, 8, 103.

26. Gargulak, J. D.; Noirot, M. D.; Gladfelter, W. L. J. Am. Chem. Soc. 1991, 113, 1054

27. Pepper, K. W.; Paisley, H. M.; Young, M. A. J. Chem. Soc. 1953 , 4097.

28. Holy, N. L.; Shalvoy, R. J. Org. Chem. 1980, 45, 1418.

29. Rode, C. V.; Gupte, S. P.; Chaudhuri, R. V.; Pirozhkov, C. D.; Lapidus, A. L. J. Mol. Catal. 1994, 91, 195.

30. Gargulak, J. D.; Berry, A. J.; Noirot, M. D.; Gladfelter, W. L. J. Am.
Chem. Soc. 1992, 114, 8933.

31. Trzeciak, A. M.; Ciunik, Z.; Ziolkowski, J. J. Organometallics 2002, 21, 132 .

32. Gargulak, J. D.; Gladfelter, W. L. J. Am. Chem. Soc. 1994, 116, 3792.

33. Johnson, K. A.; Gladfelter, W. L. Organometallics 1990, 9, 2101.

34. Holy, N. L. J. Org. Chem. 1979, 44, 239.

35. Thonde, S. S.; Kelkar, A. A.; Bhadbhade, M. M.; Chaudhari, R. V. J. Organomet. Chem. 2005, 690, 1677.

36. Albano, V. G.; Natile, G.; Panunzi, A. Coord. Chem. Rev. 1994, $133,67$.

37. Giannoccaro, P.; Tommasi, I.; Aresta, M. J. Organomet. Chem. 1994, 476, 13

38. Viege, A. S. Polyhedron 2008, 27, 3177.

39. Ozawa, F.; Kawasaki, N.; Okamoto, H.; Yamamoto, T.; Yamamoto, A. Organometallics 1987, 6, 1640.

40. Yamamoto, A.; Ozawa, F.; Osakada, K.; Huang, L.; Son, T. I.; Kawasaki, N.; Doh, M. K. Pure Appl. Chem. 1991, 63, 687. 